\title{
Evaluation of the predictive value of thorax trauma severity score (TTSS) in thoracic-traumatized patients
}

\author{
Mohamed Reda Zahran ${ }^{1 *}$ (D, Amr Abd El Monem Abd Elwahab², Mohamed Mahmoud Abo El Nasr ${ }^{3}$ \\ and Mohamed Ahmed El Heniedy ${ }^{4}$
}

\begin{abstract}
Background: Thorax trauma severity score (TTSS) combines patient-related parameters with the anatomical and physiological parameters, and it can be easily calculated in the emergency room. The validity of this score in the Egyptian population has not been tested; therefore, the objective of this study was to evaluate the prognostic role of TTSS to predict the outcome of thoracic trauma in the Egyptian patients in two centers.

Results: The study included 284 male patients (94.7\%) with a mean age of 41 years. Fifty-six patients (18.7\%) had conservative management, 216 had morbidity (72\%), and 28 patients died (9.3\%). One hundred forty-eight patients (49.3\%) had a thoracostomy tube, and thoracotomy was required in 4 patients (1.3\%). Respiratory rate above 20 cycles/min at admission was associated with mortality $(n=28(9.3 \%) ; p<0.001)$. One hundred thirty-six patients had TTSS between 0 and 5 points; 56 of them were discharged and 80 of them were admitted to the inpatient ward with a good prognosis. Twenty-four patients had TTSS between 21 and 25 points; all the 24 patients had a fatal prognosis. A cut-off value of 7 points or more of TTSS was 100\% sensitive and $97.73 \%$ specific to poor and fatal prognosis, and it was significantly associated with acute respiratory distress syndrome and the need for mechanical ventilation ( $n=64 ; p<0.001$; AUC $=0.998)$.

Conclusion: The outcome of thoracic trauma patients could be predicted based on the thorax trauma severity score. A score of 7 points or above was associated with increased morbidity, and a score of 20 points or above predicted a fatal prognosis and prolonged mechanical ventilation.
\end{abstract}

Keywords: Thorax trauma severity score, Thoracic trauma, Outcome prediction

\section{Background}

The outcome of thoracic trauma is variable and is affected by the interaction between several demographics and anatomical factors $[1,2]$. Although most of the lifethreatening injuries can be managed with minor surgical interventions [3, 4], the reported mortality in thorax trauma ranged from 15 to $25 \%$ [5]. Additionally, predictors of morbidity and mortality after thoracic trauma vary widely in the literature, and the associated extrathoracic injuries have a significant role in determining the outcome s[4].

\footnotetext{
* Correspondence: medozamzam1@gmail.com

'Emergency Medicine, Faculty of Medicine, Tanta University, Mansoura, Egypt Full list of author information is available at the end of the article
}

Several scores were developed to predict the outcomes of thoracic injuries such as the trauma and injury severity score, which is used in poly-traumatized patients, and Wagner score for the pulmonary contusion [6]. Trauma and injury severity score may underestimate thoracic injuries, in addition to its difficulty in the calculation [7]. In 2000, Pape and coworkers developed a new score, thorax trauma severity score (TTSS), that combined the patient-related parameters with the anatomical and physiological parameters [8]. TTSS is composed of five parameters; age, $\mathrm{PaO} 2 / \mathrm{FiO} 2$, pleural injuries, lung contusion, and rib fractures, and the score ranges from 0 to 25 points.

The validity of this score in the Egyptian population has not been evaluated; therefore, the objective of this 
study was to assess the prognostic role of TTSS to predict the outcome of thoracic trauma in the Egyptian patients in two centers.

\section{Methods}

\section{Patients and design}

We conducted a prospective cohort study on 300 chest trauma patients in two emergency departments during the period from May 2018 through April 2019. We included adult patients aged 18 years or above. Patients with a burn, chronic respiratory diseases, pregnancy, malignancy, end-organ failure, and patients with associated mediastinal, severe abdominal, pelvic injuries, or brain injuries with Glasgow Coma Score (GCS) below 13 were excluded.

\section{Ethical considerations}

The study was approved by the local Ethical Committee of the participating centers, and the need to obtain informed consent was waived.

\section{Trauma management}

We managed the patients according to the Advanced Trauma Life Support (ATLS) guidelines. All patients had routine laboratory investigations including random blood glucose, complete blood count, and arterial blood gases (ABG). We performed a chest X-ray, computed tomography scan, electrocardiogram for all patients, and echocardiography if a cardiac injury was suspected.

\section{Scoring system}

TTSS (thorax trauma severity score) was used to evaluate the severity of the trauma, and its components are shown in Table 1. The outcome was recorded along with the patient's data and the scoring system. The prognosis of the patients was classified into the following categories: normal; which included discharged patients, good; which included patients who were admitted to inpatient ward up to 7 days, or patients with pneumothorax, or hemothorax who were managed with simple thoracostomy, fair; which included patients who were admitted to inpatient ward more than 7 days, patients with pneumothorax with persistent air leak, patients with hemothorax who needed open thoracotomy, or patients who were admitted to ICU but did not require mechanical ventilation, poor; which included patients who were admitted to ICU and needed mechanical ventilation, fatal; which included patients who died. Morbidity was presented with a good, fair, and poor prognosis, and mortality with the fatal prognosis.

\section{Statistical analysis}

Quantitative data were presented as mean and standard deviation (SD) and qualitative data as frequencies and percentages. The chi-square or Fisher exact tests were used to compare qualitative data. A probability value of less than 0.05 was considered statistically significant. Regression analysis was used to explore the relation between TTSS, and the duration of mechanical ventilation and ICU stay. The receiver operator curve (ROC) was used to evaluate the statistical significance of sensitivity and specificity and to choose suitable cut-off points to make decisions. SPSS (Statistical Package for Social Science; SPSS for IBM, USA) version 23 for Microsoft Windows was used to perform the analysis.

\section{Results}

\section{Patients' data}

The study included 284 male patients (94.7\%), and 68 of the patients $(22.7 \%)$ were below 30 years, 108 patients $(36.0 \%)$ were between 30 and 41 years, 60 patients (20.0\%) were between 42 and 54 years, 44 patients (14.7\%) were between 55 and 70 years, 20 patients $(6.7 \%)$ were above 70 years, the mean age was 41 years and the standard of deviation was \pm 14 . Ninety-six patients (32.0\%) had penetrating trauma, and 204 patients had blunt trauma $(68.0 \%)$ including, fall from height in 40 patients (13.33\%), road traffic accident (RTA) in 52 patients $(17.33 \%)$, and crush injury in 4 patients (1.33\%).

Respiratory rate was associated with patients' outcomes; all fatalities had a respiratory rate above 20 cycle/ min $(p<0.001)$. All patients with heart rate (HR) below 100 beats per minute were discharged, and HR above 100 beats per minute was associated with an increase in morbidity and mortality $(p<0.001)$ (Table 2$)$.

Table 1 Items of the thorax trauma severity score (TTSS) [8]

\begin{tabular}{|c|c|c|c|c|c|c|}
\hline Grade & $\mathrm{PaO} 2 / \mathrm{FiO} 2$ & Rib fractures & Lung contusion & Pleura & Age & Points \\
\hline 0 & $>400$ & 0 & No & No & $<30$ & 0 \\
\hline 1 & $300-400$ & $1-3$ & Unilobar unilateral & Pneumothorax & $30-41$ & 1 \\
\hline$\|$ & $200-300$ & 3-6 (will use 4 to 6) unilateral & $\begin{array}{l}\text { Unilobar bilateral or bilobar } \\
\text { unilateral }\end{array}$ & $\begin{array}{l}\text { Hemothorax or hemo/pneumothorax } \\
\text { unilateral }\end{array}$ & $42-54$ & 2 \\
\hline III & $150-200$ & $>3$ bilateral & Bilateral $<2$ lobes & $\begin{array}{l}\text { Hemothorax or hemo/pneumothorax } \\
\text { bilateral }\end{array}$ & $55-70$ & 3 \\
\hline IV & $<150$ & Flail chest & Bilateral $\geq 2$ lobes & Tension pneumothorax & $>70$ & 5 \\
\hline
\end{tabular}

Notes: (a) For calculation of the total score, all categories are summed. (b) A minimum value is of 0 points and a maximum value is of 25 points 
Table 2 The effect of vital signs on patients' outcomes

\begin{tabular}{llllll}
\hline Vital signs & Discharge & Morbidity & Mortality & $p$ value \\
& & $N=56$ & $N=216$ & $N=28$ & \\
\hline SBP & & & & & $<0.001$ \\
& $<90$ & $0(0.00 \%)$ & $48(16.00 \%)$ & $20(6.70 \%)$ & \\
& $90-109$ & $4(1.3 \%)$ & $44(14.70 \%)$ & $0(0.00 \%)$ & \\
& $>110$ & $52(17.3 \%)$ & $124(41.30 \%)$ & $8(2.70 \%)$ & \\
RR & & & & & $<0.001$ \\
& 1219 & $52(17.30 \%)$ & $44(14.70 \%)$ & $0(0.00 \%)$ & \\
& $20-29$ & $4(1.30 \%)$ & $148(49.30 \%)$ & $0(0.00 \%)$ & \\
& $>30$ & $0(0.00 \%)$ & $24(8.00 \%)$ & $28(9.30 \%)$ & \\
HR & & & & & $<0.001$ \\
& $<100$ & $56(18.70 \%)$ & $60(20.00 \%)$ & $0(0.00 \%)$ & \\
$100-120$ & $0(0.00 \%)$ & $128(42.70 \%)$ & $12(4.00 \%)$ & \\
$120-140$ & $0(0.00 \%)$ & $28(9.30 \%)$ & $12(4.00 \%)$ & \\
$>140$ & $0(0.00 \%)$ & $0(0.00 \%)$ & $4(1.30 \%)$ &
\end{tabular}

(Categorical variables are presented as number and percentage) $H R$ : Heart rate, RR: respiratory rate, SBP: systolic blood pressure

Fifty-six patients (18.7\%) were discharged with conservative management, 216 patients had morbidity (72\%), and 28 patients died (9.3\%); all of them had lifethreatening thoracic injuries (Table 3). One hundred forty-eight patients (49.3\%) had closed thoracostomy or observation in the inpatient ward, 24 patients (8\%) needed observation ICU, and 44 patients (14.7\%) needed mechanical ventilation. Thoracotomy was required in 4 patients $(1.3 \%)$.

\section{TTSS and patients' outcome}

One hundred thirty-six patients had TTSS between 0 and 5 points; 56 of them were discharged and 80 of them were admitted to the inpatient ward with a good prognosis.

Ninety-two patients had TTSS between 6 and 10 points; 60 of them were admitted to inpatient ward (40 patients had a good prognosis 20 patients had a fair prognosis), and 32 patients were admitted to ICU (16 patients had a fair prognosis and16 patients had a poor prognosis).

Twenty-four patients had TTSS between 11 and 15 points; eight of them were admitted to the inpatient ward and had a fair prognosis, and 16 patients were admitted to ICU (8 patients had a fair prognosis and eight patients had a poor prognosis).

Twenty-four patients had TTSS between 16 and 20 points; 20 of them were admitted to ICU and had a poor prognosis and four patients died after 34-38 days of ICU stay.

Twenty-four patients had TTSS between 21 and 25 points; 12 of them died in the emergency room (ER) and 12 died after 30-40 days in the ICU. All the 24 patients had a fatal prognosis.
TTSS of 7 points or more was associated with developing acute respiratory distress syndrome (ARDS) and the need for mechanical ventilation $(n=64)$. Increased TTSS was associated with increased duration of mechanical ventilation and prolonged ICU stay $(p<0.001)$ (Figs. 1 and 2). A cut-off point of 7 or above of TTSS had a $100 \%$ sensitivity to fair, poor, and fatal prognosis, and $97.73 \%$ specificity to good and normal prognosis, with $96.88 \%$ positive predictive value and $100.00 \%$ negative predictive value. The area under the curve was 0.998 (Fig. 3).

\section{Discussion}

Our study showed that the TTSS value of 7 points or above points had 100\% sensitivity and $97.73 \%$ specificity to morbidity and mortality of patients of isolated thoracic trauma after exclusion of associated severe extrathoracic injuries. This result agrees with Elbaih and coworkers, who found that the TTSS value of 7 or above was $100 \%$ sensitive and $100 \%$ specific to poor prognosis [9]. Similarly, Elnaby and associates found that the TTSS value of 8 or above had a sensitivity of $92.3 \%$ and a specificity of $100 \%$ in the prediction of poor outcome and mortality [10]. In another study, TTSS of 8 points had a sensitivity of $80 \%$ and a specificity of $94 \%$ to predict complications and death [11].

In our study, the area under the curve was 0.998 showing that TTSS has a strong predictive value for morbidity and mortality. In a study by Hildebrand and associates, they found that TTSS had the best predictive value in comparison to CT-dependent Wagner score for pulmonary contusion and CT-independent scoring system [12]. On the other hand, Moon and associates found that thorax and trauma injury severity score (TRISS) was superior to TTSS in predicting the mortality of severe thoracic trauma [13]. However, the study was retrospective with possible selection biases.

Mortality occurred in 28 patients $(9.3 \%)$ and had TTSS ranging from 20 to 23. Subhani and coworkers had $9.8 \%$ mortality, and high TTSS was associated with increased mortality. ${ }^{(14)}$ We noticed that bilateral lung contusion more than two lobes had a significant effect on mortality, which is consistent with other studies [14].

Flail chest was associated with a mortality rate of $66 \%$ in our study. In another study, the flail chest had a mortality of $36 \%$ [14].

We found that 76 patients $(25.3 \%)$ had lung contusion injuries in the absence of thoracic bony fractures. Shorr and colleagues declared that severe parenchymal lung injuries could be present even if thoracic bony injuries are absent [15]. The majority of rib fracture injuries were managed with conservative treatment. Mechanical ventilation was not indicated except when signs of respiratory failure were developed $[16,17]$. 
Table 3 Patients' outcome distributed according to thorax trauma severity score (TTSS)

\begin{tabular}{|c|c|c|c|c|c|}
\hline \multirow[t]{3}{*}{ TTSS parameters } & & \multicolumn{3}{|c|}{ Prognosis of patients } & \multirow[t]{3}{*}{$p$ value } \\
\hline & & \multirow{2}{*}{$\begin{array}{l}\text { Discharge } \\
N=56\end{array}$} & \multirow{2}{*}{$\begin{array}{l}\text { Morbidity } \\
N=216\end{array}$} & \multirow{2}{*}{$\begin{array}{l}\text { Mortality } \\
N=28\end{array}$} & \\
\hline & & & & & \\
\hline \multirow[t]{5}{*}{ Pleural involvement } & No & $56(18.70 \%)$ & $20(6.70 \%)$ & $0(0.00 \%)$ & $<0.001$ \\
\hline & Pneumothorax & $0(0.00 \%)$ & $76(25.30 \%)$ & $0(0.00 \%)$ & \\
\hline & Hemothorax or hemo/pneumothorax unilateral & $0(0.00 \%)$ & $84(28.00 \%)$ & $0(0.00 \%)$ & \\
\hline & Hemothorax or hemo/pneumothorax bilateral & $0(0.00 \%)$ & $32(10.70 \%)$ & $8(2.70 \%)$ & \\
\hline & Tension pneumothorax & $0(0.00 \%)$ & $4(0.00 \%)$ & $20(6.70 \%)$ & \\
\hline \multirow[t]{5}{*}{ Lung contusion } & No & $56(18.70 \%)$ & 100(33.30\%) & $0(0.00 \%)$ & $<0.001$ \\
\hline & Unilobar unilateral & $0(0.00 \%)$ & $32(10.70 \%)$ & $0(0.00 \%)$ & \\
\hline & Unilobar bilateral or bilobar unilateral & $0(0.00 \%)$ & $28(9.30 \%)$ & $0(0.00 \%)$ & \\
\hline & Bilateral $<2$ lobes & $0(0.00 \%)$ & $20(6.70 \%)$ & $0(0.00 \%)$ & \\
\hline & Bilateral > 2 lobes & $0(0.00 \%)$ & $36(12.00 \%)$ & $28(9.30 \%)$ & \\
\hline \multirow[t]{5}{*}{ Rib fractures } & No & $56(18.70 \%)$ & $144(48.00 \%)$ & $0(0.00 \%)$ & $<0.001$ \\
\hline & 1-3 Fracture ribs & $0(0.00 \%)$ & $28(9.30 \%)$ & $4(1.30 \%)$ & \\
\hline & 3-6 Fracture ribs & $0(0.00 \%)$ & $28(9.30 \%)$ & $0(0.00 \%)$ & \\
\hline & $>3$ Bilateral fracture ribs & $0(0.00 \%)$ & $8(2.70 \%)$ & $8(2.70 \%)$ & \\
\hline & Flail chest & $0(0.00 \%)$ & $8(2.70 \%)$ & $16(5.30 \%)$ & \\
\hline \multirow[t]{5}{*}{$\mathrm{PaO} 2 / \mathrm{FiO} 2$} & $>400$ & $56(18.70 \%)$ & $24(8.00 \%)$ & $0(0.00 \%)$ & $<0.001$ \\
\hline & $300-400$ & $0(0.00 \%)$ & $80(26.70 \%)$ & $0(0.00 \%)$ & \\
\hline & $200-300$ & $0(0.00 \%)$ & $60(20.00 \%)$ & $0(0.00 \%)$ & \\
\hline & $150-200$ & $0(0.00 \%)$ & $28(9.30 \%)$ & $0(0.00 \%)$ & \\
\hline & $<150$ & $0(0.00 \%)$ & $24(8.00 \%)$ & $28(9.30 \%)$ & \\
\hline
\end{tabular}

(Categorical variables are presented as number and percentage)

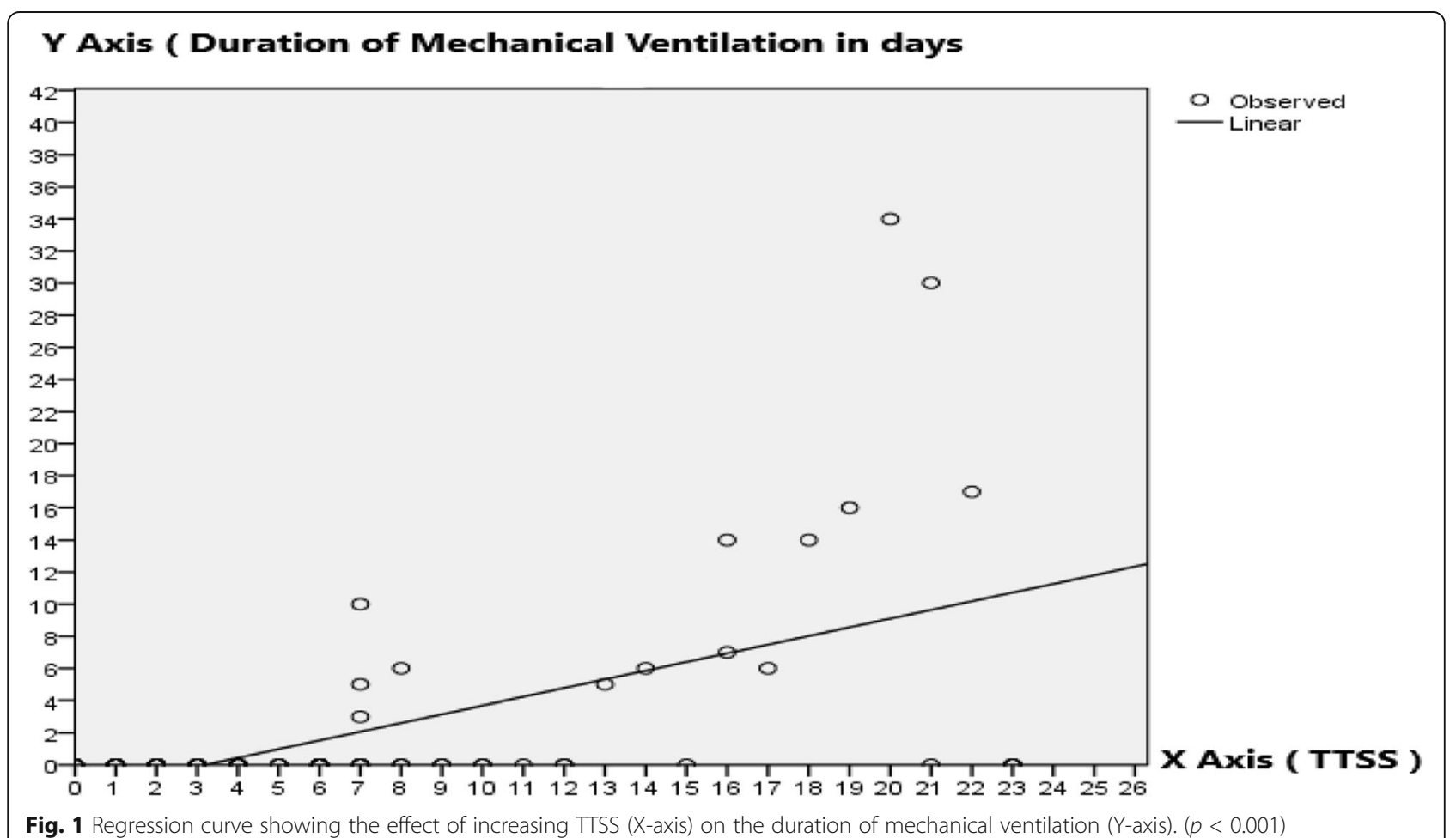

Fig. 1 Regression curve showing the effect of increasing TTSS (X-axis) on the duration of mechanical ventilation $(Y$-axis). $(p<0.001)$ 

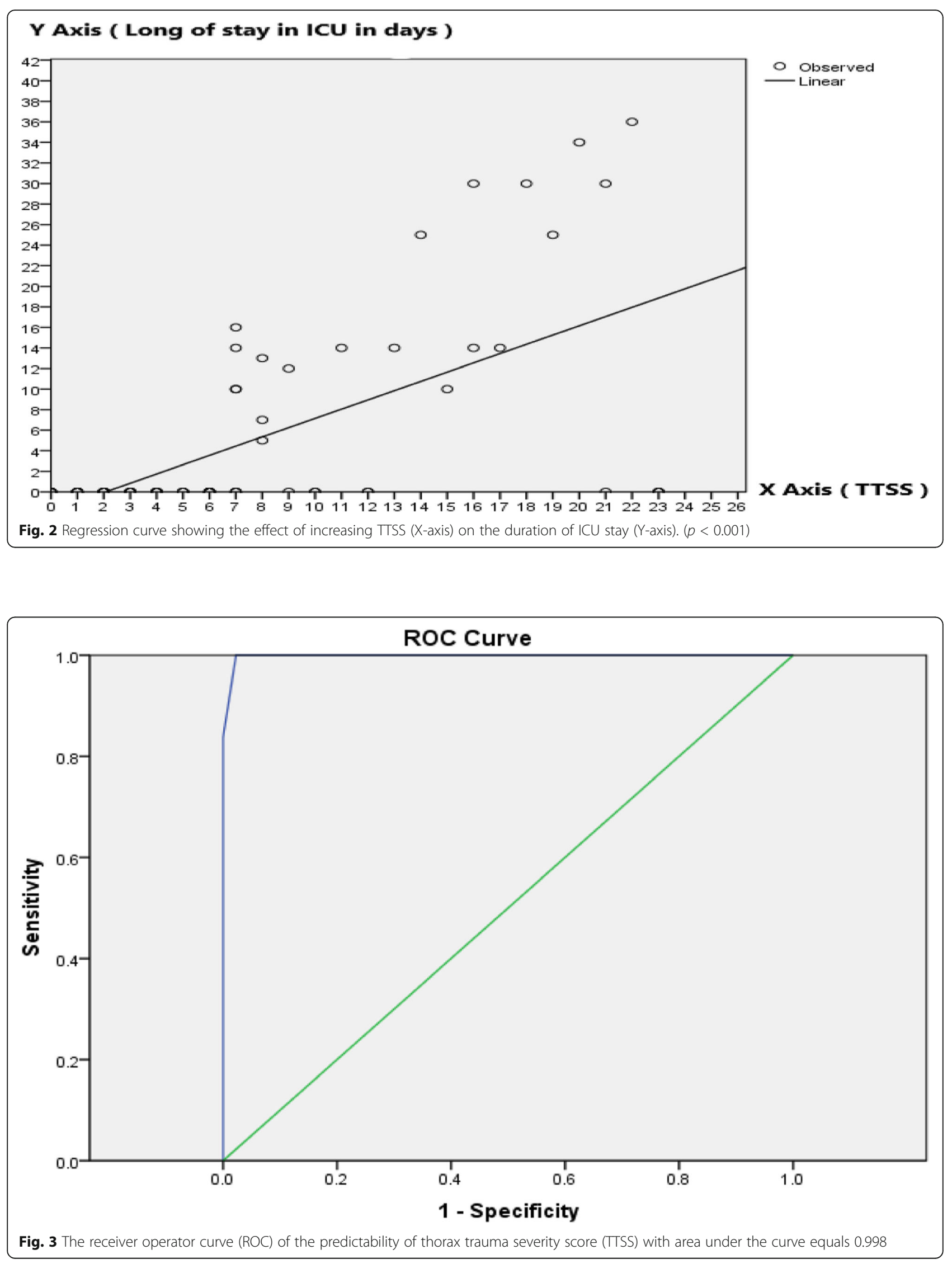
In our study, most patients were managed with simple procedures without any major complications, and 56 patients (18.7\%) were discharged with conservative treatment. Four patients had thoracotomy, and this trend in managing chest trauma can be explained by the advancement of the imaging systems, new therapeutics, and minimally invasive procedures. All of those had contributed in decreasing the morbidity and mortality of thoracic trauma injuries [18].

We noticed in our study that low TTSS values were associated with a good prognosis, and the high TTSS values were associated with higher morbidity and mortality. Correspondingly, Subhani and colleagues stated that low TTSS values were associated with a normal and good prognosis, and high TTSS values were associated with a good, fair, poor, and fatal prognosis [14].

We found that with increasing TTSS above 7, there was an increased probability of mechanical ventilation, and duration of mechanical ventilation and ICU stay. This study comes in agreement with Balkan and associates, who found that there was an association between morbidity, mortality, and the need for mechanical ventilation [19].

TTSS, with a cut-off value of 7 points or above, was associated with ARDS, which is consistent with other studies [20,21].

\section{Limitation of the study}

The age is a major component of the score, although it was not significant, which affected the sensitivity and specificity of the score.

Flail chest, either a small or large-sized segment in chest fractures parameter in TTSS has a score of 5 points; however, small-sized flail segments can be managed with conservative treatment. Fracture of the first or second ribs is an indicator of severe trauma; despite that, they take 1 point on TTSS.

\section{Conclusion}

The outcome of thoracic trauma patients could be predicted based on the thorax trauma severity score.

A score of 7 points or above was associated with increased morbidity, and patients require close monitoring.

A score of 20 points or above predicted a fatal prognosis and prolonged mechanical ventilation.

\section{Abbreviations}

ARDS: Acute respiratory distress syndrome; ER: Emergency Room; HR: Heart rate; ICU: Intensive Care Unit; RR: Respiratory rate; RTA: Road traffic accident; SBP: Systolic blood pressure; TRISS: Trauma and Injury Score; TTSS: Thorax trauma severity score

\section{Authors' contributions}

MZ participitated in collection of data and writing the thesis. AA was the supervisor participated in statistical analysis, writing the thesis and pioneering the ideas. MMA and MAE participated in writing and guiding the work. All authors have read and approved the manuscript.

\section{Funding}

Not applicable.

Availability of data and materials

Not applicable for ethical cause.

\section{Ethics approval and consent to participate}

The present prospective study has been approved by the local ethical committee (Quality

Management Unit ) in the Faculty of Medicine in Tanta University. The need to obtain informed consent was waived by the local ethical committee. The reference number is not applicable and not available.

\section{Consent for publication}

A written consent was obtained from each patient participitated in the medical research.

\section{Competing interests}

The authors declare that they have no competing interests.

\section{Author details}

${ }^{1}$ Emergency Medicine, Faculty of Medicine, Tanta University, Mansoura, Egypt. ${ }^{2}$ Cardiothoracic Surgery, Faculty of Medicine, Tanta University, Tanta, Egypt. ${ }^{3}$ Cardiothoracic Surgery, Faculty of Medicine, Tanta University, Tanta, Egypt. ${ }^{4}$ Emergency Medicine Department, Faculty of Medicine, Tanta University, Tanta, Egypt.

Received: 19 October 2019 Accepted: 5 January 2020

Published online: 14 January 2020

\section{References}

1. Bozorgi F, Mirabi A, Chabra A, Mirabi R, Hosseininejad SM, Zaheri H (2018) Mechanisms of Traumatic Injuries in Multiple Trauma Patients. Int J Med Invest 7(2):7-15

2. Dongel I, Coskun A, Ozbay S, Bayram M, Atli B (2013) Management of thoracic trauma in emergency service: Analysis of 1139 cases. Pakistan journal of medical sciences 29(1):58

3. Walls, R., Hockberger, R., \& Gausche-Hill, M. (2017). Rosen's Emergency Medicine-Concepts and Clinical Practice E-Book ( $9^{\text {th }}$ ed., Vol 1 , pp. 382-391) . Elsevier Health Sciences.

4. Mirka H, Ferda J, Baxa J (2012) Multidetector computed tomography of chest trauma: indications, technique and interpretation. Insights into imaging 3(5):433-449

5. Peters S, Nicolas V, Heyer CM (2010) Multidetector computed tomographyspectrum of blunt chest wall and lung injuries in polytraumatized patients. Clinical radiology 65(4):333-338

6. Mommsen P, Zeckey C, Andruszkow H, Weidemann J, Frömke C, Puljic P et al (2012) Comparison of different thoracic trauma scoring systems in regards to prediction of post-traumatic complications and outcome in blunt chest trauma. Journal of surgical research 176(1):239-247

7. Domingues, C. D. A., Nogueira, L. D. S., Settervall, C. H. C., \& Sousa, R. M. C. D. (2015). Performance of Trauma and Injury Severity Score (TRISS) adjustments: an integrative review. Revista da Escola de Enfermagem da USP, 49(SPE), 138-146.

8. Pape HC, Remmers D, Rice J, Ebisch M, Krettek C, Tscherne H (2000) Appraisal of early evaluation of blunt chest trauma: development of a standardized scoring system for initial clinical decision making. J Trauma Acute Care Surgery 49(3):496-504

9. Elbaih AH, Elshapowry IM, Kalil NG, El-Aouty H (2016) Evaluation of thoracic trauma severity score in predicting the outcome of isolated blunt chest trauma patients. IJSM 2(3):100-106

10. Elnaby, M.A., Saffan, M.M., Wahdan, A.M., \& Saad, D. (2018). Assesement Of Isolated Blunt Chest Trauma Patients In Benha University Hospital According To Thoracic Trauma Severity Score 
11. Casas IM, Marchante MAA, Paduraru M, Olea AIF, Nolasco A, Medina JC (2016) Thorax trauma severity score: is it reliable for patient's evaluation in a secondary level hospital? Bulletin Emergency Trauma 4(3):150

12. Hildebrand F, van Griensven M, Garapati R, Krettek C, Pape HC (2002) Diagnostics and scoring in blunt chest trauma. Eur J Trauma 28(3):157-167

13. Moon SH, Kim JW, Byun JH, Kim SH, Choi JY, Jang IS et al (2017) The thorax trauma severity score and the trauma and injury severity score: Do they predict in-hospital mortality in patients with severe thoracic trauma?: A retrospective cohort study. Medicine 96(42)

14. Subhani SS, Muzaffar MS, Khan MI (2014) Comparison of outcome between low and high thoracic trauma severity score in blunt trauma chest patients. J Ayub Med College Abbottabad 26(4):474-477

15. Shorr RM, Crittenden M, Indeck M, Hartunian SL, Rodriguez A (1987) Blunt thoracic trauma. Analysis of 515 patients. Annals Surgery 206(2):200

16. Simon B, Ebert J, Bokhari F, Capella J, Emhoff T, Hayward T III et al (2012) Management of pulmonary contusion and flail chest: an Eastern Association for the Surgery of Trauma practice management guideline. J Trauma Acute Care Surgery 73(5):S351-S361

17. Menditto VG, Gabrielli B, Marcosignori M, Screpante F, Pupita G, Polonara S et al (2012) A management of blunt thoracic trauma in an emergency department observation unit: pre-post observational study. J Trauma Acute Care Surgery 72(1):221-226

18. Trinkle JK, Richardson JD, Franz JL, Grover FL, Arom KV, Holmstrom FM (1975) Management of flail chest without mechanical ventilation. Annals Thoracic Surgery 19(4):355-363

19. Balkan EM, Oktar LG, Kayt-Cangtr A (2002) Emergency thoracotomy for blunt thoracic trauma. Annals Thoracic Cardiovasc Surgery 8(2):78-82

20. Aukema TS, Beenen LF, Hietbrink F, Leenen LP (2011) Validation of the Thorax Trauma Severity Score for mortality and its value for the development of acute respiratory distress syndrome. Open Access Emergency Med 3:49

21. Daurat A, Millet I, Roustan JP, Maury C, Taourel P, Jaber $S$ et al (2016) Thoracic Trauma Severity score on admission allows to determine the risk of delayed ARDS in trauma patients with pulmonary contusion. Injury 47(1): 147-153

\section{Publisher's Note}

Springer Nature remains neutral with regard to jurisdictional claims in published maps and institutional affiliations.

\section{Submit your manuscript to a SpringerOpen ${ }^{\circ}$ journal and benefit from:}

- Convenient online submission

- Rigorous peer review

- Open access: articles freely available online

- High visibility within the field

- Retaining the copyright to your article

Submit your next manuscript at $\boldsymbol{\nabla}$ springeropen.com 